needed in the pursuit of technical excellence. As a first step, the readiness of 84 surgeons $^{2}$ to reveal their results, warts and all, shows courage. Others should follow their example.

${ }^{1}$ Ritchie JK. Results of surgery for inflammatory bowel disease: a further survey of one hospital region. $\operatorname{Br} \operatorname{Med} \mathcal{F} 1974 ; \mathrm{i}: 264-8$.

2 Fielding LP, Stewart-Brown S, Blesovsky L, Kearney G. Anastomotic integrity after operations for large-bowel cancer: a multicentre study. Br Med F 1980;281:411-4.

${ }^{3}$ Everett WG. A comparison of one layer and two layer techniques for colorectal anastomosis. Br 7 Surg 1975;62:135-40.

4 Goligher JC, Lee PWG, Simpkins KC, Lintott DJ. A controlled comparison of one-layer and two-layer techniques of suture for high and low colorectal anastomoses. Br $\mathcal{F}$ Surg 1977;64:609-14.

5 Sharefkin J, Joffe N, Silen W, Fromm D. Anastomotic dehiscence after low anterior resection of the rectum. Am $\mathcal{F}$ Surg 1978;135:519-23.

- Tagart REB. Colorectal anastomosis: factors influencing success. $\mathcal{F}$ Soc Med $1981 ; 74: 111-8$.

7 Goligher JC. Recent trends in the practice of sphincter-saving excision for rectal cancer. Ann R Coll Surg Engl 1979;61:169-76.

${ }^{8}$ Heald RJ. Towards fewer colostomies-the impact of circular stapling devices on the surgery of rectal cancer in a district hospital. Br $\mathcal{F}$ Surg $1980 ; 67: 198-200$.

- Matheson NA, Irving AD. Single layer anastomosis after rectosigmoid resection. BrF Surg 1975;62:239-42.

\section{Child abuse: the swing of the pendulum}

Until the late 1950s, the child abuse syndrome went unrecognised by doctors. Indeed, some have alleged that the inability or unwillingness of medical men to acknowledge the possibility that parents could batter their children was the reason why it was hidden for so long.

Once the revelations of Caffey, ${ }^{12}$ Silverman, ${ }^{3}$ and Kempe et $a^{4}$ reached the medical press and then the lay media, the medical profession rapidly made up for lost time in suspecting and seeking out deliberate injury in childhood. Before long doctors were looking at every injured child with suspicionladen eyes. This was right, since only by lowering the threshold of suspicion-previously high enough to be a barrier to recognition-could cases be detected and attempts made to reduce the incidence. With a $10 \%$ mortality rate and a $60 \%$ recurrence rate, such alertness was well justified in trying to prevent a condition that ended in death, permanent brain damage, or any lesser degree of trauma.

In many places all injuries in children were assumed to be due to battering unless proved otherwise. Some disquieting evidence suggests that the pendulum of suspicion has swung a little too far, perhaps overcompensating for the former tardiness in recognising the syndrome. But there are more immediate reasons for this overenthusiasm in declaring obscure injuries to be due to abuse by parents-namely, the not infrequent and vehemently publicised lapses by which doctors or social agencies or both have failed to prevent a death. These have induced both a defensive attitude in physicians and a sometimes overdemanding clamour for information by the community services that have to monitor and try to prevent further abuse. At this point there are two dangers. Firstly, the often indistinct line between the diagnostic criteria for accident and abuse is crossed without sufficient grounds. This danger has always been present and only clinical experience and acumen can resolve the problem. Secondly, in cases where the risk is marginal the delicate parent-doctor relationship may be impaired by demands for the breach of confidentiality needed to register the child as being at risk. In some recent cases this fragile relationship has been prejudiced or even ruined because social and legal agencies have insisted on being informed about the potential risk at a stage when a diagnosis of battering was premature. When a parent with whom a doctor has been working hard for weeks to establish such a relationship suddenly learns that her child has been placed on the non-accidental injury risk register, the painfully constructed-and perhaps already unstablerapport with her doctor may be irretrievably lost, possibly to the detriment of the child.

Where a child who has not been previously notified to the appropriate agency dies or receives serious injury the doctor often comes in for much retrospective recrimination. Nevertheless, he may feel quite justified in having maintained professional secrecy, even though in the event he was wrong. $\mathrm{He}$ may have taken a calculated risk in his efforts to support an atrisk or handicapped family by his own efforts, rather than invoke the procedure of the multidisciplinary case conference. The practitioner who thus attempts such intensive and prolonged counselling may be forced to forgo the supportive services of a social worker, since, being bound to report to a wider group, the latter could reverse the delicate process of repairing a bruised family. As with alleged negligence, the doctor cannot insure against errors of judgment and if his clinical impressions led him in good faith to believe that his course of action was correct, he should not be condemned with the benefit of hindsight.

The swing of this particular pendulum has other aspects. For instance, general practitioners frequently absent themselves from case conferences on children at risk, one reason being that they are worried about breaking confidentiality and appearing to betray the parents. In the hospital service too there are repercussions. Relatively inexperienced junior staff in casualty departments are reluctant to exclude the possibility of non-accidental injury even when no hint exists, raising suspicion in the minds of colleagues, nurses, and parents when none is justified. This has led to parents-sometimes even professional people-failing to avail themselves of the casualty services for the quite innocent minor injuries that children suffer. The "register" has indeed become a fearful thing to some people.

Certainly professional confidentiality counts for little compared with the life of an abused child. In marginal cases, however, a large proportion turn out not to be abused children. Though missing a case of abuse where the signs are clear is both tragic and reprehensible, a false accusation that parents are abusing their child is also damaging. Judging whether abuse has taken place may be one of the most difficult and agonising decisions a doctor has to make. The new twist is the tendency to demand that a doctor should keep the community services posted, as of right, of every suspicion, even before he has made up his mind about the true diagnosis. He may well need to cultivate the perhaps tenuous relationship with the parents until he is clearer about the true state of affairs within the family. Imperious demands for information by bodies not having immediate responsibility for care of patients may be counterproductive if they damage this delicate personal relationship.

${ }^{1}$ Caffey J. Multiple fractures in the long bones of infants suffering from chronic subdural hematoma. American Fournal of Roentgenology 1946; 56:163-73.

2 Caffey J. Some traumatic lesions in growing bones other than fractures and dislocations: clinical and radiological features. The Mackenzie Davidson memorial lecture. Br f Radiol 1957;30:225-38.

3 Silverman FN. The roentgen manifestations of unrecognised skeletal tr.uma in infants. American fournal of Roentgenology 1953;69:413-27.

${ }^{4}$ Kempe CH, Silverman FN, Steele BF, Droegemueller W, Silver HK. T'he battered-child syndrome. F $A M A 1962 ; 181$ :17-24. 